\title{
Correction to: Predictors of the chest CT score in COVID-19 patients: a cross-sectional study
}

\author{
Niloofar Ayoobi Yazdi ${ }^{1 \dagger}$, Abdolkarim Haji Ghadery ${ }^{2 \dagger}$, SeyedAhmad SeyedAlinaghi ${ }^{3}$, Fatemeh Jafari ${ }^{4}$, \\ Sirous Jafari ${ }^{4}$, Malihe Hasannezad ${ }^{4}$, Hamid Emadi Koochak ${ }^{4}$, Mohammadreza Salehi ${ }^{4}$, \\ Seyed Ali Dehghan Manshadi ${ }^{4}$, Mohsen Meidani ${ }^{4}$, Mahboubeh Hajiabdolbaghi ${ }^{4}$, Zahra Ahmadinejad ${ }^{4}$, \\ Hossein Khalili ${ }^{5}$, Mohammad-Mehdi Mehrabi Nejad ${ }^{2^{*} \dagger}$ and Ladan Abbasian ${ }^{4^{*}+}$ (])
}

\section{Correction to: Virology Journal (2021) 18:225} https://doi.org/10.1186/s12985-021-01699-6

Following publication of the original article [1], the authors identified an error in the author name of SeyedAhmad SeyedAlinaghi and in the author name of Mohammad-Mehdi Mehrabi Nejad.

The incorrect author name is: Seyed Ahmad Seyedalinaghi

The correct author name is: SeyedAhmad SeyedAlinaghi

The incorrect author name is: Mohammad-Mehdi Mehrabinejad

The correct author name is: Mohammad-Mehdi Mehrabi Nejad

The original article has been corrected.

The original article can be found online at https://doi.org/10.1186/s12985021-01699-6.

\footnotetext{
*Correspondence: mm-mehrabinejad@alumnus.tums.ac.ir; la-abbasian@sina. tums.ac.ir

${ }^{\dagger}$ Niloofar Ayoobi Yazdi and Abdolkarim Haji Ghadery are joint first authors

†Ladan Abbasian and Mohammad-Mehdi Mehrabi Nejad are joint senior authors

${ }^{2}$ Department of Radiology, Advanced Diagnostic and Interventional Radiology Research Center(ADIR), Tehran University of Medical Sciences,

Tehran, Iran

${ }^{4}$ Department of Infectious Diseases, Imam Khomeini Hospital, Imam Khomeini Hospital Complex, Tehran University of Medical Sciences, Blv. Keshavarz, Tehran, Iran

Full list of author information is available at the end of the article
}

\begin{abstract}
Author details
${ }^{1}$ Department of Radiology, Imam Khomeini Hospital, Tehran University of Medical Sciences, Tehran, Iran. ${ }^{2}$ Department of Radiology, Advanced Diagnostic and Interventional Radiology Research Center(ADIR), Tehran University of Medical Sciences, Tehran, Iran. ${ }^{3}$ Iranian Research Center for HIV/AIDS, Iranian Institute for Reduction of High-Risk Behaviors, Tehran University of Medical Sciences, Tehran, Iran. ${ }^{4}$ Department of Infectious Diseases, Imam Khomeini Hospital, Imam Khomeini Hospital Complex, Tehran University of Medical Sciences, Blv. Keshavarz, Tehran, Iran. ${ }^{5}$ Department of Pharmacotherapy, Imam Khomeini Hospital Complex, Tehran University of Medical Sciences, Tehran,
\end{abstract} Iran.

Published online: 06 December 2021

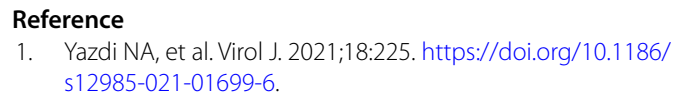

\section{Publisher's Note}

Springer Nature remains neutral with regard to jurisdictional claims in published maps and institutional affiliations.

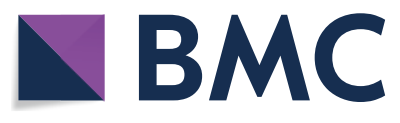

(c) The Author(s) 2021. Open Access This article is licensed under a Creative Commons Attribution 4.0 International License, which permits use, sharing, adaptation, distribution and reproduction in any medium or format, as long as you give appropriate credit to the original author(s) and the source, provide a link to the Creative Commons licence, and indicate if changes were made. The images or other third party material in this article are included in the article's Creative Commons licence, unless indicated otherwise in a credit line to the material. If material is not included in the article's Creative Commons licence and your intended use is not permitted by statutory regulation or exceeds the permitted use, you will need to obtain permission directly from the copyright holder. To view a copy of this licence, visit http://creativecommons.org/licenses/by/4.0/. The Creative Commons Public Domain Dedication waiver (http://creativecommons.org/publicdomain/zero/1.0/) applies to the data made available in this article, unless otherwise stated in a credit line to the data. 